\title{
RELAÇÕES DE SABER E DE PODER NOS DISCURSOS SOBRE SEXUALIDADE
}

\section{RELATIONSHIPS OF KNOW AND POWER IN THE DISCUSSIONS ON SEXUALITY}

Paula Maria Trabuco

Teresa Cristina Barbo Siqueira

\begin{abstract}
RESUMO: Esse artigo tem o objetivo buscar refazer a história da sexualidade no Ocidente, desde as suas raízes mais longínquas, procurando traçar um panorama da evolução dos costumes nos quais a sexualidade se desenvolveu e assim compreender as diversas formas de vivenciá-la no decorrer dos tempos até a atualidade. Hoje temos uma visão de sexualidade e uma utilização do sexo como mercadoria na sociedade capitalista, pois tudo o que se refere a esse assunto "vende". Mas, se retomarmos a história, perceberemos que a sexualidade reveste-se de significações diferentes em cada época e sofre influências de uma estrutura sócio-históricacultural que define valores e regras e dá contornos à forma de entendê-la e vivenciá-la. Buscamos como base teórica os autores Foucault (1985, 1993 1998), Nunes $(1987,1996,1997)$, Louro (2000), Merleau-Ponty $(1975,1996)$ Vigotski $(1934 / 1998,1984 / 2002,1994,1996,2004)$ entre outros. A análise das raízes históricas da sexualidade permite reforçar o argumento de que a sociedade em que vivemos ainda se encontra dividida, hierarquizada e marcada por conceitos e discursos de séculos anteriores que abordam a sexualidade como um objeto a ser escondido e regrado.
\end{abstract}

Palavras-chave: Discursos. Repressão Sexual. Sexualidade.

ABSTRACT: This article aims to retake the history of sexuality in the West, from its most distant roots, seeking to outline the evolution of customs in which sexuality has developed and thus to understand the various ways of experiencing it in the course of time until the actuality. Today we have a vision of sexuality and a use of sex as a commodity in capitalist society, since everything that refers to it "sells." But if we return to history, we will realize that sexuality has different meanings in each epoch and is influenced by a socio-historical-cultural structure that defines values and rules and contours the way of understanding and experiencing it. We sought as a theoretical basis the authors Foucault (1985, 1993 1998), Nunes $(1987,1996,1997)$, Louro (2000), Merleau-Ponty (1975, 1996) Vigotski (1934/1998, 1984/2002, 1994, 1996, 2004), among others. The analysis of the historical roots of sexuality reinforces the argument that the society in which we live is still divided, hierarchical and marked by concepts and discourses of previous centuries that approach sexuality as an object to be hidden and regulated.

Keywords: Speeches. Sexual Repression. Sexuality.

\section{INTRODUÇÃO}

Educação, Psicologia e Interfaces, Volume 2, Número 1, p. 47-70, Janeiro/Abril, 2018

ISSN: 2594-5343 DOI: https://doi.org/10.37444/issn-2594-5343.v2i1.117 
Vivemos num ambiente "sexualizado" e os discursos sobre a sexualidade se entrelaçam confusos, mistificadores, apelativos, enquadradores e questionantes em todas as esferas do cotidiano. Hoje temos uma visão de sexualidade e uma utilização do sexo como mercadoria na sociedade capitalista, pois tudo o que se refere a esse assunto "vende". Ao mesmo tempo existe um discurso mudo, proibido sobre a sexualidade que perpassa diversas épocas da nossa história. Portanto, para entendermos os significados da sexualidade nos dias atuais, precisamos fazer uma viagem pela história, refletir sobre o passado, pois é nele que encontramos as raízes do presente. Como orientador dessa discussão escolhemos Michel Foucault o historiador das proibições e do poder repressivo que buscava o discurso das "verdades" produzidas e analisava o poder que se exerce sobre a loucura e a sexualidade.

Para Foucault (1985, p. 10) a sexualidade deve ser compreendida como "experiência", isto é, entendida como uma "correlação, em uma cultura, entre os campos de saber, tipos de normatividade e formas de subjetividade". Assim, é um dispositivo histórico no qual há incontáveis maneiras de expressar e vivenciar o prazer. É atravessado por ideologias, concepções, saberes e formas de controle próprios do período a que se referem. Nesse contexto, "a sexualidade passa a ganhar significação a partir de múltiplos discursos, sendo estes que regulam, que normatizam, que instauram saberes, que produzem 'verdades"” (LOURO, 2010, p.12). Eles são variáveis de acordo com o momento histórico e definem as identidades sociais, incluindo as sexuais e de gênero, e estas constituem os sujeitos e suas relações com a cultura, com as instituições e com o uso do corpo e dos prazeres.

Foucault (1985, p. 9) relata que em meados do século XIX, na era dita Vitoriana ${ }^{1}$, a "sexualidade foi cuidadosamente encerrada", confiscada do campo social para segregar-se à família conjugal, exatamente para dentro do quarto do casal burguês, passando a ter a função de reprodução e sendo proibida de ser mencionada e vivênciada no meio social. Seu discurso aberto só teria vez nos lugares considerados ilícitos, na sexualidade dos loucos ou por meio da figura da prostituta, que representava o prazer a ser trocado por preço alto. Já não se podia falar sobre sexo. As crianças, seres considerados assexuados, foram interditadas desse assunto; fechavam seus os olhos e tapavam-lhe os ouvidos onde quer que ele se manifestasse. Impunha-se assim um silêncio geral. A sexualidade estava interditada, escondida e muda. Nunes (1987, p. 69) contribui com a discussão ao dizer que nessa época

O sexo é reduzido ao privado e com fim procriativo. A concepção de racionalidade e eficiência burguesa soma-se à produtividade. $\mathrm{O}$ sexo subjetivo, humano, prazeroso, desaparece. O corpo é negado no trabalho e na repressão sexual. $O$ "eu" corporal não existe e sim a civilidade e a máscara social. Sobre o sexo nasce a cultura da vergonha e do pecado em níveis tão profundos que nem mesmo a Idade Média tinha conseguido.

Educação, Psicologia e Interfaces, Volume 2, Número 1, p. 47-70, Janeiro/Abril, 2018 ISSN: 2594-5343 DOI: https://doi.org/10.37444/issn-2594-5343.v2i1.117 
A partir de Freud (1856-1939) esse tema passou a ser tratado de forma médica, com precaução e certo conformismo, assegurados por uma "ciência dos sexos" ou prática da sexologia. Antes de Freud, a criança era considerada um ser isento de expressão sexual. Com seus estudos, ele descobriu e demonstrou a existência de uma sexualidade infantil e foi o primeiro teórico a considerar com naturalidade os atos e efeitos sexuais das crianças, como a ereção, a masturbação e mesmo as simulações sexuais. Foi quem mais se preocupou com o estudo da sexualidade e inverteu a concepção existente sobre o sexo: afirmava que a libido ${ }^{2}$ não era a causa de doenças e distúrbios físicos e psíquicos, mas sim a repressão dessa libido.

Freud (2006) foi percebendo que a causa das neuroses não estava na hereditariedade, mas nas questões sexuais, na história sexual dos pacientes desde a tenra idade. Em seus últimos estudos afirmou que a civilização depende dessa repressão sexual e por isso ter um caráter agressivo e destrutivo. Embora fosse necessário diminuir a ignorância e preconceitos, não se poderia eliminar - para o bem da humanidade, segundo ele - toda e qualquer a repressão. Diante disso suas ideias, no início muito contestadas, paulatinamente revolucionaram as ciências humanas, sendo uma das descobertas mais importante freudiana foi de que

[...] qualquer que seja o caso e qualquer que seja o sintoma que tomemos como ponto de partida, no fim chegamos infalivelmente ao campo da experiência sexual. Aqui, portanto, pela primeira vez, parece que descobrimos uma precondição etiológica dos sintomas histéricos (FREUD, 2006, p. 196).

A natureza humana precisa de controle para viver em sociedade, pois a tarefa da civilização é oferecer segurança ao indivíduo, “[...] é evitar o sofrimento, colocando o seu prazer em segundo plano" (FREUD, 1974, p. 73). Dessa forma, valoriza-se o pensamento sobre o que sentimos e fazemos (intelectualismo) e abandonam-se o afeto e os sentimentos sexuais.

Para Foucault (1974), a sexualidade humana está dividida em duas concepções básicas que delimitam a forma de entendê-la e vivenciá-la: a arte erótica e a ciência sexual. Em algumas sociedades, como as da Índia e China, essa verdade é extraída do que se chama de ars erótica ${ }^{3}$, ou seja, do próprio prazer, encarado como prática e recolhido 
como experiência. Nessas sociedades a grande experiência do sexo é o prazer e dele vem a verdade - ressaltar o que se sente, buscar formas de intensificá-lo e fazer com que as novas gerações possam valorizá-lo. Aprimorar o prazer é poderosa justificativa para a arte erótica. Nessa perspectiva, as sociedades que vivem essa arte, também chamada arte do erotismo, não discursam sobre o sexo, mas o mantêm em segredo e o transmitem culturalmente para as gerações mais novas, como experiência de vida. Segundo Foucault (1988, p.57):

Dessa forma constitui-se um saber que deve permanecer secreto, não
em função de uma suspeita de infâmia que marque seu objeto, porém
pela necessidade de mantê-lo na maior discrição, pois segundo a
tradição, perderia sua eficácia e sua virtude ao ser divulgado. [...] Os
efeitos dessa arte magistral, bem mais generoso do que faria supor a
aridez de suas receitas, devem transfigurar aquele sobre quem recaem
seus privilégios: domínio absoluto do corpo, gozo excepcional,
esquecimento do tempo e dos limites, elixir de longa vida, exílio da
morte e de suas ameaças.

Em nossa sociedade essa verdade vem de uma prática scentia sexualis ${ }^{4}$ um podersaber. Para esse autor a ciência sexual refere-se historicamente à definição normatizadora e controladora da sexualidade, que produz tanto os condicionantes da normalidade como o reconhecimento das anomalias e aberrações sexuais. Trata-se de ordenar o que é patológico, mórbido, passível ou não de tratamento, com a finalidade de estabelecer dispositivos de controle e segregação. Hoje se sabe que a anatomia, a fisiologia e a patologia dos órgãos sexuais e da reprodução não dão conta do universo da sexualidade, pois enfatizam apenas a parte física e intelectual e se esquecem da parte afetiva e

subjetiva. Para compreender a sexualidade no seu âmbito abrangente, nascida na dinâmica da sociedade, tanto quanto do indivíduo, é necessário muito mais que uma abordagem biológica dos mecanismos controladores, de seus sistemas e possibilidades.

Quando as práticas sexuais passam a ter regras, exigências naturais e cerimoniais humanas, é gerada uma repressão sexual ${ }^{5}$, definida por Chauí (1992, p. 9) como “[...] um conjunto de interdições, permissões, normas, valores, regras estabelecidas histórica e culturalmente para controlar o exercício da sexualidade".

A repressão não é apenas uma imposição exterior que despenca sobre nós, mas também um fenômeno sutil de interiorização das proibições e interdições externas (e consequentemente, também das permissões) que se converte em proibições e interdições (e permissões) internas, vividas por nós sob a forma do desagrado, da inconveniência, da vergonha, do

Educação, Psicologia e Interfaces, Volume 2, Número 1, p. 47-70, Janeiro/Abril, 2018 ISSN: 2594-5343 DOI: https://doi.org/10.37444/issn-2594-5343.v2i1.117 
sofrimento e da dor (CHAUÍ, 1992, p. 13).

Essa repressão é eficaz quando consegue ocultar ou dissimular, por meio de proibições e permissões, o caráter sexual daquilo que está sendo reprimido. Elas são interiorizadas pela consciência por meio do discurso social, muitas vezes disfarçado de uma "certa educação sexual". Nesse sentido esse artigo tem o objetivo buscar refazer a história da sexualidade no Ocidente, desde as suas raízes mais longínquas, procurando traçar um panorama da evolução dos costumes nos quais a sexualidade se desenvolveu e assim compreender as diversas formas de vivenciá-la no decorrer dos tempos até a atualidade. Para isso, utilizou-se da metodologia descrita na seção seguinte.

\section{MATERIAL(IS) E MÉTODO(S)}

Adotamos como método a pesquisa bibliográfica; segundo Lima e Mioto (2007, p.38), ela "[...] implica em um conjunto ordenado de procedimentos, de busca por soluções, atento ao objeto de estudo e que por isso, não pode ser aleatório". Por isso, é de suma importância a delimitação dos critérios e dos procedimentos metodológicos (tipo de pesquisa, universo delimitado, instrumento de coleta de dados).

Com o objetivo de investigar o problema apresentado, mostramos o estudo dos conceitos que desvelam a sexualidade humana, de forma a abranger a sua história sociocultural e como essa história tem influenciado a Educação Sexual vivenciada nas escolas. O olhar que irá orientar nosso processo de investigação e análise neste trabalho é o fenomenológico, que visa trazer à luz, de modo diferenciado, o que se mostra dos fatos a serem observados, o que se apresenta por si ao observador e ouvinte.

Para Coldro (2000) caracteriza-se pelo uso de técnicas não quantitativas, com propostas críticas, em busca de relacionar o fenômeno à essência (eidos). A validação da prova científica é buscada no processo lógico da interpretação e na capacidade de reflexão do pesquisador sobre o fenômeno que é o seu objeto de estudo. Sabemos que falar sobre sexualidade já é um desafio, por si só. As resistências são muitas e é exigido de todos os envolvidos revisar conceitos, superar preconceitos e estereótipos, além de olhar reflexivamente para a própria sexualidade, lidar com tabus, medos e vergonhas.

\section{RESULTADOS E DISCUSSÃO}

Educação, Psicologia e Interfaces, Volume 2, Número 1, p. 47-70, Janeiro/Abril, 2018

ISSN: 2594-5343 DOI: https://doi.org/10.37444/issn-2594-5343.v2i1.117 
A partir do século XVI, paulatinamente, o sexo foi colocado em discurso. As técnicas de poder sobre o sexo disseminaram a implantação dos discursos e da normatização das sexualidades polimorfas. Essa repressão reduziu a sexualidade ao nível de linguagem. Segundo Foucault (1985, p.22),

[...] definiu-se de maneira muito mais estrita onde e quando não era possível falar dele; em que situações, entre quais locutores, e em que relações sociais; estabeleceram-se, assim, regiões, senão de silêncio absoluto, pelo menos de tato e discrição: entre pais e filhos, por exemplo, ou educadores e alunos, patrões e serviçais.

Em outras palavras, não se falava sobre sexo como algo natural, mas sim como algo cheio de proibições e restrições. Criou-se o discurso da racionalidade sexual, a começar na forma de higienização e controle de doenças, uma necessidade de regular o sexo por meio de discursos úteis e públicos. Tinha-se nesse momento a repressão moderna do sexo, coincidente com o desenvolvimento do capitalismo. Estreitava-se assim a relação do sexo com o poder, na qual

[...] cumpre falar do sexo como de uma coisa que não se deve simplesmente condenar ou tolerar, mas gerir, inserir em sistemas de utilidade, regular para bem de todos, fazer funcionar segundo um padrão ético. O sexo não se julga apenas, administra-se. Sobreleva-se ao poder público; exige procedimentos de gestão; deve ser assumido por discursos analíticos (FOUCAULT, 1988, p.27).

O poder sobre o sexo se estabeleceu pelo impositivo do discurso do "não pode" contra o "pode", ou seja, pela afirmação do que é proibido ou então permitido. Os principais instrumentos desse poder são o castigo e a penitência, de forma que todos os modos de dominação e submissão/sujeição se reduzam ao efeito da obediência. Dessa forma, fomos transformados numa sociedade cheia de tabus e preconceitos que engendra diversos discursos e permissões para um controle normativo social da sexualidade. Com isso Foucault (1988) aponta para o início de uma moralização do comportamento infantil, de um disciplinamento sob a repressão do sexo para a inibição de certos comportamentos em sociedade.

O essencial é bem isso: que o homem ocidental há três séculos tenha permanecido atado a essa tarefa que consiste em dizer tudo sobre seu sexo; que, a partir da época clássica, tenha havido uma majoração constante e uma valoração cada vez maior do discurso sobre o sexo; e que se tenha esperado desse discurso, cuidadosamente analítico, efeitos múltiplos de deslocamento, de intensificação, de reorientação, de modificação sobre o próprio desejo (FOUCAULT, 1985a, p. 26).

Educação, Psicologia e Interfaces, Volume 2, Número 1, p. 47-70, Janeiro/Abril, 2018 
O discurso sobre o sexo foi incorporado aos manuais de confissão da Idade Média, nos quais a descrição minuciosa do ato sexual em execução era necessária para que a confissão fosse completa. "A pastoral cristã inscreveu, como dever fundamental, a tarefa de fazer passar tudo o que se relaciona com o sexo pelo crivo interminável da palavra" (FOUCAULT, 1985, p. 24). E ainda ressalta que

[...] confessam-se os crimes, os pecados, os pensamento e os desejos; confessam-se passado e sonhos; confessa-se a infância; confessam-se as próprias doenças e misérias; [...] confessa-se em público, em particular, aos pais, aos educadores, ao médico, àqueles a quem se ama; [...] confessa-se - ou é forçado a confessar (FOUCAULT, 1985, p. 59).

A confissão da verdade se inscreveu no cerne dos procedimentos de individualização pelo poder; era uma das técnicas altamente valorizadas para produzir a verdade e difundia efeitos na justiça, na medicina, na pedagogia e nas relações familiares e amorosas (FOUCAULT, 1985).

A confissão fermenta o poder de saber, e o poder é que aprisiona. É esta a reflexão que Foucault formaliza em tom de denúncia:

É preciso estar muito iludido com esse ardil interno da confissão para atribuir à censura, à interdição de dizer e de pensar, um papel fundamental; é necessária uma representação muito invertida do poder, para nos fazer acreditar que é de liberdade que nos falam todas essas vozes que há tanto tempo, em nossa civilização, ruminam a formidável injunção de devermos dizer o que somos, o que fazemos, o que recordamos e o que foi esquecido, o que escondemos e o que se oculta, o que não pensamos e o que pensamos inadvertidamente. Imensa obra a que o ocidente submeteu gerações para produzir - enquanto outras formas de trabalho garantiam a acumulação do capital - a sujeição dos homens, isto é, sua constituição como "sujeitos", nos dois sentidos da palavra (FOUCAULT, 1988, p. 60).

Nascia, então, uma incitação política, religiosa, econômica e técnica quanto a falar de sexo, não sob a forma de teoria geral, mas sob forma de análise, de contabilidade, de classificação e especificação por pesquisas quantitativas ou causais. Assim, para além dos discursos da moral, buscaria-se o discurso da racionalidade, em que se cumpre falar sobre sexo como uma coisa que não deve ser condenada ou tolerada, mas gerida e inserida em sistema de utilidade. O sexo é administrado, passa a haver uma "polícia do sexo", isto é, uma necessidade de regulá-lo por meio de discursos úteis e não pelo rigor da proibição

Educação, Psicologia e Interfaces, Volume 2, Número 1, p. 47-70, Janeiro/Abril, 2018

ISSN: 2594-5343 DOI: https://doi.org/10.37444/issn-2594-5343.v2i1.117 
(FOUCAULT, 1985, p 27).

Segundo Nunes (1987, p. 69), sentimo-nos culpados frente ao sexo e nos parece necessário confessar, quer ao padre, ao psicanalista, ao médico ou à nossa própria racionalidade, as nossas "faltas" sexuais. "Essa culpa se inoculou através de rígida pregação, o poder da Igreja em formar o imaginário moral-social”.

Não se falou menos sobre sexo, mas se falou de outra maneira, com outras palavras. Criaram-se: a taxa de natalidade, a idade do casamento, os nascimentos legítimos e ilegítimos, a precocidade e a frequência das relações sexuais, entre outras formas de ligar o futuro e a fortuna de uma sociedade à maneira como cada qual usa seu sexo. Constituiu-se uma análise das condutas sexuais nos limites entre o biológico e o econômico. Segundo Foucault (1985, p.29), entre o Estado e o indivíduo o sexo se tornou objeto de disputa pública, em que o "Estado saiba o que se passa com o sexo dos cidadãos e o uso que dele fazem e, também, que cada um seja capaz de controlar sua prática”. Surgiu então uma incitação política, econômica e técnica em falar do sexo na forma de análise, de contabilidade, classificação e especificação, e não a partir de uma teoria da sexualidade.

Em relação às crianças, Foucault (1985) afirma que no início do século XVIII, passou a ser dada uma grande importância à masturbação infantil, tratada como epidemia capaz de afetar a saúde e o desenvolvimento da vida adulta. Essa sexualização requereria uma rede de vigilância, por parte da família e da escola, que possibilitasse observações e saberes que acarretariam lucros operacionais, à medida que intensificasse o controle sobre a vida das crianças e produzisse a disciplinarização da vida escolar e da casa.

O sexo das crianças passou a ser carregado de um discurso mudo. Falava-se dele de outra maneira, por outras pessoas, a partir de outros pontos de vista. Discurso mudo no sentido de que não era dito de forma explícita, mas sim sob o que Foucault (1985) chama de "discurso interno da instituição", visto nos colégios, por exemplo: em seus dispositivos arquitetônicos, regulamentos de disciplina, configuração do espaço das salas, forma das mesas, arranjo dos pátios e recreios, distribuição dos dormitórios, regulamentos elaborados para a vigilância do recolhimento e do sono, entre outras manifestações. Tudo fala de maneira mais prolixa à sexualidade das crianças.

Só podiam falar sobre sexo das crianças os locutores qualificados, ou seja,

[...] os médicos se dirigem aos diretores dos estabelecimentos e aos

Educação, Psicologia e Interfaces, Volume 2, Número 1, p. 47-70, Janeiro/Abril, 2018 
professores, também dão conselhos as família; os pedagogos fazem projetos e os submetem as autoridades; os professores se voltam para os alunos, fazem-lhe recomendações e para eles redigem livros de exortação, cheios de conselhos médicos e de exemplos edificantes (FOUCAULT, 1985, p. 31).

O sexo é assim tratado como um problema clínico e de saúde. Segundo Chauí (1992), estudado e investigado em um contexto médico-científico que se preocupa em classificar todos os casos de patologia física e psíquica, em estudar as doenças sexualmente transmissíveis, os desvios e as anomalias, as "aberrações sexuais", com a finalidade de estabelecer higiene e uma normatização das condutas consideradas anormais e desviantes. Trata-se de

Prazer em exercer um poder que questiona, fiscaliza, espreita, espia, investiga, apalpa, revela; e, prazer de escapar a esse poder. Poder que se deixa invadir pelo prazer que persegue - poder que se afirma no prazer de mostrar-se, de escandalizar, de resistir (CHAUÍ, 1992, p. 8889).

É, portanto, um poder que coage e passa ser incorporado no cotidiano sob o mito de uma liberdade e uma verdade ligadas a uma expressão obrigatória e exaustiva de um segredo individual - "Inocenta-o, resgata-o, purifica-o, livra-o de suas faltas, libera-o, promete-lhe a salvação" (FOUCAULT, 1985, p 61). Dessa forma a Educação Sexual limitou-se aos princípios gerais e às regras de prudência, a um discurso confessionário e científico que funciona por meio de uma verdade regulada.

Scientia sexualis contra ars erótica, um processo dialético entre as abordagens aqui destacadas, sexualidade vista através da verdade do prazer: prazer em sabê-la, exibila e descobri-la; fascinar-se ao vê-la, dizê-la, cativar e capturar os outros por meio dela, enfim, prazer específico do discurso verdadeiro sobre o prazer. Daí a multiplicação e a intensificação dos prazeres ligados à produção da verdade sobre o sexo. E o que estão em jogo? Poder e prazer.

A sexualidade é o nome que se pode dar a um dispositivo histórico: não à realidade subterrânea que se apreende com dificuldade, mas à grande rede da superfície em que a estimulação dos corpos, a intensificação dos prazeres, a incitação ao discurso, a formação dos conhecimentos, o reforço dos controles e das resistências, encadeiam-se uns aos outros, segundo algumas grandes estratégias de saber e de poder (FOUCAULT, 1985, p. 100),

Educação, Psicologia e Interfaces, Volume 2, Número 1, p. 47-70, Janeiro/Abril, 2018

ISSN: 2594-5343 DOI: https://doi.org/10.37444/issn-2594-5343.v2i1.117 
O poder, segundo Foucault (1985), não deve ser entendido como um conjunto de instituições e aparelhos que garantem a sujeição dos cidadãos a um Estado determinado, isto é, a soberania do Estado sobre o corpo social. Deve-se entender o poder como uma multiplicidade de correlações entre formas de domínio que constituem uma organização e nela se exercem, formando cadeias (ou sistemas) e estratégias cujo esboço geral ou cristalização institucional toma corpo nos aparelhos estatais, na formulação da lei e nas hegemonias sociais. Portanto, “o poder não é uma instituição e nem uma estrutura, não é uma certa potência de que alguns sejam dotados: é o nome dado a uma situação estratégica complexa numa sociedade determinada" (FOUCAULT, 1985, p 89). Além disso, específica que,

O poder seria, essencialmente, aquilo que dita a lei, no que diz respeito ao sexo. O que significa, em primeiro lugar, que o sexo fica reduzido, por ele, a regime binário: lícito e ilícito, permitido e proibido. [...] A forma pura do poder se encontraria na função do legislador; e seu modo de ação com respeito ao sexo seria jurídico discursivo (FOUCAULT, 1988, p. 81).

Foucault (1985) concebe poder com base em três afirmações: O poder não é essencialmente repressivo (já que incita, suscita e produz); ele é algo que se exerce, não que se possui (só se possui sob uma forma determinável: classe, e determinada: Estado); e passa tanto pelos dominados quanto pelos dominantes (permeia todas as forças em relação). Dessa forma, o que o poder coloca em questão são as relações entre os indivíduos, e nessas relações seu exercício se configura quando há ação sobre ações: uma relação de poder é a ação que não age direta e imediatamente sobre os outros, mas sobre a própria ação.

Em relação à sexualidade, o poder se estabelece na forma da interdição:

[...] não te aproximes, não toques, não consumas, não tenhas prazer, não fales, não apareças; em última instância não existirás, a não ser na sombra e no segredo. [...] Renuncia a ti mesmo sob pena de seres suprimido; não apareças se não quiseres desaparecer. Tua existência só será mantida à custa de tua anulação (FOUCAULT, 1988, p.81-82).

Ocorre também a censura:

[...] afirmar que não é permitido, impedir que se diga, nega que exista. Formas aparentemente difíceis de conciliar. Mas é aí que é imaginada uma espécie de lógica em cadeia, que seria característica dos

Educação, Psicologia e Interfaces, Volume 2, Número 1, p. 47-70, Janeiro/Abril, 2018 
mecanismos de censura: liga o inexistente, o lícito e o informulável de tal maneira que cada um seja, ao mesmo tempo, princípio e efeito do outro: do que é interdito não se deve falar até ser anulado no real; o que é inexistente não tem direito a manifestação nenhuma, mesmo na ordem da palavra que enuncia sua inexistência; e o que deve ser calado encontra-se banido do real como o interdito por excelência (FOUCAULT, 1988, p.81-82).

Não há dúvida de que os estudos de Foucault sobre as relações históricas entre poder, sexo e discurso apontam para algo tão negativo quanto perigoso, a ponto de precisar ser dominado e combatido visando ao direcionamento utilitário. O domínio do sexo produz a obediência, e a obediência é condição fundamental para a manutenção do estado social do poder.

Foucault (1985) constrói uma nova hipótese acerca da sexualidade humana, ao argumentar que esta não deve ser concebida como um dado da natureza que o poder tenta reprimir, mas sim ser encarada como produto do encadeamento da estimulação dos corpos, da intensificação dos prazeres, da incitação ao discurso, da formação dos conhecimentos e do reforço dos controles e resistências. Portanto, as sexualidades são socialmente construídas. Para Merleau-Ponty (1996, p. 219),

É a sexualidade que faz com que um homem tenha uma história. Se a história sexual de um homem oferece a chave de sua vida, é porque na sexualidade do homem projeta-se sua maneira de ser a respeito do mundo, quer dizer, a respeito do tempo e a respeito dos outros homens.

É por meio da sexualidade que o homem projeta sua maneira de ser em relação ao mundo, isto é, com relação ao tempo e aos outros homens. A sexualidade que emana do corpo, que garante a própria história e que projeta o ser no mundo como um único deve ser compreendida como uma forma indissociável da representação humana, como “coextensiva à vida" (MERLEAU-PONTY, 2006, p. 233) e por isso entendida em todos os seus aspectos.

Segundo Foucault (1985), deparamo-nos com uma produção da sexualidade como um saber que diz o verdadeiro e o falso sobre sexo e cujos pontos de partida foram as regras e as técnicas para maximizar a vida, para o crescimento demográfico e o controle familiar. Essa estratégia acabou por sexualizar tudo, criando uma verdadeira "monarquia do sexo" na qual não só ele é vigiado e regulado, mas se torna fonte da inteligibilidade do nosso ser.

Educação, Psicologia e Interfaces, Volume 2, Número 1, p. 47-70, Janeiro/Abril, 2018

ISSN: 2594-5343 DOI: https://doi.org/10.37444/issn-2594-5343.v2i1.117 
A partir de então, constituiu-se um tipo de poder chamado por Foucault (1988) de" poder disciplinar", que objetiva, individualiza e classifica aqueles aos quais é aplicado. Ele atua no corpo dos humanos individualizando-os; carimba uma identidade conhecida e produz um comportamento útil e dócil para o desenvolvimento de uma sociedade mais complexa.

Foucault (1988, p. 100) vai além nas dimensões política e social da sexualidade, pois, a seu ver, "pode-se admitir, sem dúvida, que as relações de sexo tenham dado lugar, em toda sociedade, a um dispositivo de aliança: sistema de matrimônio, de fixação e desenvolvimento dos parentescos, de transmissão dos nomes e dos bens". Como justificativa, considera tal assertiva.

O dispositivo de aliança se estrutura em torno de um sistema de regras que define o permitido e o proibido, o prescrito e o ilícito; o dispositivo de sexualidade funciona de acordo com técnicas móveis, polimorfas e conjunturais de poder. $\mathrm{O}$ dispositivo de aliança conta, entre seus objetivos principais, o de reproduzir a trama de relações e manter a lei que as rege; o dispositivo de sexualidade engendra, em troca, uma extensão permanente dos domínios e das formas de controle. Para o primeiro, o que é pertinente é o vínculo entre parceiros com status definido; para o segundo, são as sensações do corpo, a qualidade dos prazeres, a natureza das impressões, por tênues ou imperceptíveis que sejam. Enfim, se o dispositivo de aliança se articula fortemente com a economia devido ao papel que pode desempenhar na transmissão ou na circulação das riquezas, o dispositivo de sexualidade se liga à economia através de articulações numerosas e sutis, sendo o corpo a principal corpo que produz e consome (FOUCAULT, 1988, p. 101).

$\mathrm{O}$ autor infere que

Não se deve descrever a sexualidade como um ímpeto rebelde, estranha por natureza e indócil por necessidade a um poder que, por sua vez, esgota-se na tentativa de sujeitá-la e muitas vezes fracassam em dominá-la inteiramente. Ela aparece mais como um ponto de passagem particularmente denso pelas relações de poder: entre homens e mulheres, entre jovens e velhos, entre pais e filhos, entre educadores e alunos, entre padres e leigos, entre administração e população. Nas relações de poder, a sexualidade não é o elemento mais rígido, mas um dos dotados de maior instrumentalidade, utilizável no maior número de manobras e podendo servir de ponto de apoio, de articulação às mais variadas estratégias (FOUCAULT, 1985 p. 100)

\subsection{Sexualidade na contemporaneidade}

Educação, Psicologia e Interfaces, Volume 2, Número 1, p. 47-70, Janeiro/Abril, 2018

ISSN: 2594-5343 DOI: https://doi.org/10.37444/issn-2594-5343.v2i1.117 
Após os anos de 1860/1870 a sexualidade começou a se transformar, passando a ser objeto de atenção do Estado, da medicina, das leis, além de continuar a ser tema da religião. Preocupava-se cada vez mais com a organização e controle das populações, com medidas para garantir a vida e a produtividade dos povos. Segundo Louro (2009, p. 22),

Os Estados voltavam-se para a disciplinarização e regulação da família, da reprodução e das práticas sexuais. Nas décadas finais desse século, surgiu uma nova disciplina, a sexologia: médicos e também filósofos, moralistas e pensadores passaram a fazer proclamações e "descobertas" sobre o sexo. Eles inventavam classificações de sujeitos e de práticas sexuais, passavam a determinar o que era ou não normal, adequado, sadio.

É nesse contexto que, ao final do século XIX, surgiram a homossexualidade e o sujeito homossexual. Vale ressaltar que relações amorosas e sexuais entre sujeitos de um mesmo sexo existiam antes dessa época, em todas as sociedades; contudo, tais relações não eram compreendidas ou nomeadas como homossexualidade; eram caracterizadas como sodomia ${ }^{6}$ ou então como um pecado que qualquer um poderia cometer. A partir desse momento histórico essa prática amorosa e sexual passou a ter outro significado, a indicar um tipo particular de pessoa, um tipo social, uma "espécie" de gente que se desviara da "normalidade" (LOURO, 2009). Portanto, estabeleciam-se hierarquias que marcavam os diferentes tipos de sujeitos e os tipos de práticas sexuais.

Tais "verdades" a respeito da sexualidade foram colocadas em funcionamento nos diversos discursos sociais, inclusive na educação, o que resultou em transformações e arranjos que foram se modificando ao longo do tempo nas formas de organização da família e do trabalho e nas possibilidades de comunicação entre indivíduos, Estados e grupos. A compreensão desse processo nos leva a construir e entender o olhar que temos hoje sobre a sexualidade.

Enquanto nas décadas anteriores os discursos sobre sexo e sexualidade limitavamse aos confessionários ou à ciência e à religião - no tocante ao que deveria ou não ser feito, como deveria, por quem ou quando -, posteriormente passaram a ganhar voz as mulheres, os gays e as lésbicas. Eles começaram a falar de suas experiências e práticas amorosas, sexuais e de trabalho, bem como de seus projetos, sonhos e ambições. Louro (2009) afirma que todo esse processo e os movimentos desses grupos fizeram com que as verdades sobre a sexualidade e sobre os gêneros se multiplicassem e se diversificassem

Educação, Psicologia e Interfaces, Volume 2, Número 1, p. 47-70, Janeiro/Abril, 2018 ISSN: 2594-5343 DOI: https://doi.org/10.37444/issn-2594-5343.v2i1.117 
na contemporaneidade; as "certezas" que antes definiam e rotulavam a sexualidade deixaram “[...] de ser únicas, estáveis, seguras, infalíveis” (LOURO, 2009, p. 32).

Para Foucault (1988), enquanto o século XVII caracterizou a sexualidade pela pudicícia $^{7}$ imperial, os séculos XIX e $\mathrm{XX}$ foram marcados pela conquista dos afrouxamentos dos mecanismos de repressão. Para o autor, a sexualidade está no centro de tudo,

[...] estamos numa sociedade do 'sexo', ou melhor, 'da sexualidade': os mecanismos de poder se dirigem ao corpo, à vida, ao que a faz proliferar, ao que reforça a espécie, seu vigor, sua capacidade de dominar, ou sua aptidão para ser utilizada. Saúde, progenitura, raça, futuro da espécie, vitalidade do corpo social - o poder fala da sexualidade e para a sexualidade; quanto a esta, não é marca ou símbolo, é objeto e alvo (FOUCAULT, 1988, p.138).

Nesta era do discurso livre, aberto, repleto de inovações tecnológicas que driblam até mesmo o tempo e a distância, são possibilitadas relações virtuais e seleção de parceiros candidatos a relacionamentos que se dizem amorosos. Segundo Louro (2009, p. 21),

[...] vendem-se produtos apelando para o sexo; celebram-se corpos saudáveis e com "tudo em cima"; uma porção de especialistas e celebridades pretende nos ensinar técnicas e estratégias para manter os corpos jovens e ativos; médicos e psiquiatras, além de conselheiros e orientadores de todo tipo, prescrevem práticas sexuais que consideram adequadas e condenam outras.

Neste sentido, Nunes (1996, p. 229) alerta que:

É de fundamental importância destacarmos a necessidade da crítica à sexualidade consumista, esta sim também desumanizadora, reduzindo corpos e pessoas a um conjunto de experiências vorazes, frustrantes e compensatórias de grandes ausências de sentido, sugerindo a existência de problemas, muito mais complexos.

É necessário registrar, neste resgate histórico da sexualidade na contemporaneidade, o que significou o advento da Síndrome da Imunodeficiência Adquirida (AIDS), que inicialmente era tida como "doença gay". De modo especial, com seu surgimento ampliou-se muito a discussão a respeito da sexualidade, particularmente da homossexualidade, em várias instâncias sociais, inclusive nas escolas, o que estimulou a criação de projetos de Educação Sexual.

Segundo Louro (2009, p. 34), 
É possível dizer que, na contemporaneidade, os atravessamentos das fronteiras de gênero e sexualidade parecem mais frequentes ou, quem sabe talvez sejam, simplesmente, mais visíveis. O fato é que, hoje, as classificações binárias de masculinidade e feminilidade ou de heterossexualidade e homossexualidade não dão mais conta das possibilidades de práticas e de identidades experimentadas pelos sujeitos. Isso não significa que se transite livremente entre esses territórios. As consequências para quem tem a ousadia de fazer tal atravessamento são, em geral, a punição, o isolamento ou, eventualmente, a reeducação com vistas ao retorno ao "bom caminho".

É preciso reconhecer que vivemos no que alguns filósofos chamam de sociedade pansexualista (onde a sexualidade está em tudo, da propaganda ao discurso político, na representação dos presidentes, na vida, nas simbologias e nas utopias). Portanto, é necessário que pais e professores tenham uma reflexão, um debate com aprofundamento da compreensão da sexualidade para uma intervenção qualitativa, subjetiva, ética e informativa, capaz de dar às novas gerações segurança e referência na vivência social e pessoal da sexualidade.

\subsection{Sexualidade e o corpo}

Na contemporaneidade, o que se percebe é que o discurso sobre a sexualidade envolve também um discurso e um poder sobre corpo tornaram-se mercadoria; são vistos, mais do que nunca, em sua perspectiva "utilitária", justamente em um momento histórico em que o foco da vida deveria ser totalmente voltado para o trabalho e a produção. Todavia, o capitalismo os apreendeu e os incorporou à sua máquina de consumo (NUNES, 1987).

No capitalismo o corpo se submete, torna-se corpo-instrumento voltado para a produção e, consequentemente, para o sustento e a vida de todos. Nessa visão, o trabalho da sociedade capitalista é natural, desejável e necessário para o desenvolvimento humano. Para Marx (2010, p.31),

[...] a economia nacional conhece o trabalhador apenas como animal de trabalho, como uma besta reduzida às mais estritas necessidades corporais". E esse trabalhador alienado da sua atividade humana, ou seja, no seu trabalho produz a si mesmo e torna-se mercadoria, mas não se apropria do objeto, e assim ocorre a desvalorização do mundo dos homens. O corpo utilitário, dominado, material de fácil substituição pela revolução industrial, nos moldes atuais do modo de produção capitalista torna-se valiosa mercadoria de consumo.

Por ser a forma como se expressam as necessidades humanas, uma vez que é para ele que convergem interesses sociais, políticos e econômicos, o corpo tem acumulada

Educação, Psicologia e Interfaces, Volume 2, Número 1, p. 47-70, Janeiro/Abril, 2018

ISSN: 2594-5343 DOI: https://doi.org/10.37444/issn-2594-5343.v2i1.117 
uma série de práticas e discursos. É por meio dele que, segundo Siqueira (2010), o homem estrutura sua forma de agir, se comportar, pensar e educar, desenvolvendo sua corporeidade. Esta se vê transformada em mercadoria nas relações capitalistas atuais, à medida que o corpo é minimizado a um utilitário, tornado um produto e uma mercadoria de consumo.

Para Merleau-Ponty (1996, p. 122), o corpo não é apenas um objeto, tampouco uma mercadoria, uma mera coisa; ele transforma a ideia em coisas, “[...] é o veículo do ser no mundo, e ter um corpo é, para um ser vivo, juntar-se a um meio definido, confundirse com certos projetos e empenhar-se continuamente neles".

Segundo Foucault (1998) o corpo é moldado, ganha forma na sua relação com os mecanismos de poder presentes nos discursos e práticas sociais e constitui subjetividades em relação e em função de si, ou seja, numa realidade biopolítica ${ }^{8}$, na qual se inicia o controle social:

O controle da sociedade sobre os indivíduos não se opera simplesmente pela consciência ou pela ideologia, mas começa no corpo, com o corpo. Foi no biológico, no somático, no corporal que, antes de tudo, investiu a sociedade capitalista. O corpo é uma realidade bio-política (FOUCAULT 1998, p.80).

Para Foucault (1998, p.146), "o domínio e a consciência de seu próprio corpo só puderam ser adquiridos pelo efeito do investimento do corpo pelo poder: a ginástica, os exercícios, o desenvolvimento muscular, a nudez, a exaltação do belo corpo".

Historicamente, constata-se que os sujeitos tornam-se conscientes de seus corpos à medida que há um investimento disciplinar sobre eles. Quando o poder é aí exercido, "[...] emerge inevitavelmente a reivindicação do próprio corpo contra o poder" (FOUCAULT, 1998, p.146). Buscamos todas formas de resposta, de resistência, de transformação ou de subversão para as imposições e os investimentos disciplinares feitos sobre nossos corpos.

Foucault (1998) relata que, aproximadamente no início do século XVIII, o poder sobre o corpo era exercido por meio dos suplícios, uma punição pública utilizada no criminoso de forma que produzisse um sofrimento gradual e hierarquizado que acarretava muitas vezes a morte. O tipo de ferimento físico, a intensidade e o tempo dos sofrimentos eram correlacionados com a gravidade da infração e com o nível social da vítima. $\mathrm{Na}$ segunda metade do século XVIII surgiu a prisão como forma de disciplina, pautada em uma constante vigilância e controle dos corpos. Era uma forma de "não tocar mais nos corpos" (FOUCAULT, 1998, p. 14), mas também uma arte de sensações insuportáveis

Educação, Psicologia e Interfaces, Volume 2, Número 1, p. 47-70, Janeiro/Abril, 2018 ISSN: 2594-5343 DOI: https://doi.org/10.37444/issn-2594-5343.v2i1.117 
sob uma economia de direitos suspensos que utilizava métodos de controle minucioso sobre o corpo por meio do domínio do tempo, do espaço, dos movimentos, dos gestos e das atitudes.

Desse modo, produziam-se corpos submissos, exercitados e dóceis. Por muito tempo, segundo Foucault (1998), o corpo foi colocado nessa posição de instrumento, uma forma de privar o indivíduo de sua liberdade, considerada ao mesmo tempo um direito e um bem. O corpo era colocado num sistema de coação e de privação, de obrigações e de interdições. E é por meio do corpo que se disciplina o sexo.

Os mecanismos de poder disciplinar não se restringem às prisões, mas têm aplicação nas escolas por meio das orientações político-pedagógicas, das leis e dos currículos, que enfatizam cada vez mais o autodisciplinamento e a autorregulamentação dos estudantes. Foucault (1998) chama as práticas que induzem a esses comportamentos de "tecnologias do eu". Elas agem sobre o corpo e produzem regimes político-corporais particulares; funcionam como regimes de verdade que utilizam relações disciplinares de poder-saber ${ }^{9}$ como peças fundamentais.

Os métodos que permitem o controle do corpo, que sujeitam o indivíduo constantemente, podem ser chamados de disciplina e "[...] aparecem como maneiras de aprendizagem que permitem aos indivíduos se integrarem a essas exigências gerais" (FOUCAULT, 1998, p. 183). A escola é o espaço onde esse poder disciplinar produz saber, a fim de dominar os corpos com maior eficiência. O currículo escolar está entre o saber e o poder, a representação e o domínio, o discurso e a regulação; condensa relações de poder que são interessantes para o processo de formação de determinadas subjetividades sociais. Desse modo, "a escola torna-se um aparelho de aprender onde cada aluno, cada nível e cada momento, se combinados da maneira correta, são permanentemente utilizados no processo geral de ensino" (FOUCAULT, 1998, p. 140).

$\mathrm{Na}$ escola disciplinar, todas as atividades são desenvolvidas com uma minúcia perfeita, com etapas rigorosamente estabelecidas pelos professores e seguidas pelos alunos. Estes são acompanhados constantemente durante todo o seu processo de educação por meio de um controle diário de seus corpos e das atividades, das quais é exigida eficiência na execução. A escola serve ao adestramento para a obtenção de corpos vigorosos, obedientes e livres da devassidão. Nessa perspectiva, é preciso separar os 
corpos, torná-los visíveis para a observação. É preciso também punir atrasos, ausências, grosserias, desobediência e indecência, e essa punição pode ocorrer na forma de pequenas humilhações e privações. Foucault (1998, p. 125) nos apresenta um exemplo:

\begin{abstract}
Vejamos o exemplo da "classe". Nos colégios dos jesuítas, encontravase ainda uma organização ao mesmo tempo binária e maciça: as classes, que podiam ter até duzentos ou trezentos alunos, eram divididas em grupos de dez; cada um desses grupos, com seu decurião ${ }^{10}$ eram colocados em um campo, ou romano ou o cartaginês; a cada decúria correspondia uma decúria adversa. A forma geral era a da guerra e da rivalidade; o trabalho, o aprendizado, a classificação eram feitos sob a forma de justa, pela defrontação dos dois exércitos; a participação de cada aluno entrava nesse duelo geral; ele assegurava, por seu lado, a vitória ou as derrotas de um campo; e os alunos determinavam um lugar que correspondia à função de cada um e a seu valor de combatente no grupo unitário de sua decúria. [...] Dessa forma, cada um também se define pelo lugar que ocupa na série, pela distância que o separa dos outros. A unidade não é, portanto nem o território, nem o local, mas a posição na fila [...] a disciplina, arte de dispor em fila e da técnica para dispor em arranjos. Ela individualiza os corpos por uma localização que não os implanta, mas os distribui e os faz circular numa rede de relações.
\end{abstract}

Nos dias atuais, vemos escolas em que os alunos também são isolados, organizados de forma metódica em seu espaço físico meticulosamente estruturado, para que possam ser vigiados sob o menor esforço e tenham o menor contato possível entre si. As salas mapeadas, nas quais cada aluno possui um lugar marcado e registrado, são organizadas analiticamente para a economia do poder.

A história da sexualidade empreendida até aqui faz valer o dito de que toda história é história contemporânea, pois tem um compromisso com o presente, ou seja, interroga o passado tomando como referência questões que fazem parte da nossa vida, como a existência de desigualdades de classe, de gênero ou de opção sexual, os significados das aparências, as manifestações da sexualidade, a luta por direitos, o papel da família, do Estado, das religiões e das ciências no cotidiano, os limites e as possibilidades de acesso à cultura, entre outras.

Foucault (1998) diz que, embora o esclarecimento sobre sexualidade seja útil, fazse necessária a percepção de toda a teia que a envolve, pois parece haver entre os indivíduos uma intensa vontade de saber, acompanhada de uma sensação de que nesse campo há sempre algo desconhecido, meandros que precisam ser desvendados. É preciso buscar um campo teórico e científico acerca da verdade sobre a sexualidade. O autor

Educação, Psicologia e Interfaces, Volume 2, Número 1, p. 47-70, Janeiro/Abril, 2018 ISSN: 2594-5343 DOI: https://doi.org/10.37444/issn-2594-5343.v2i1.117 
estabelece que não pode haver conceito de verdade se não houver conceito de poder. A verdade é marcada pelas contingências históricas e pela não-razão, é constituída de acordo com o meio social de cada grupo, ou seja, o que é verdade para um grupo não necessariamente o é para outro. É também factual que cada sociedade tem o poder de considerar um enunciado falso ou verdadeiro e, dentro de suas concepções, aplicar as sanções previstas em suas leis.

A trajetória dos comportamentos sexuais do nascimento até a morte deve vir à tona para que possamos apreender, conhecer e classificar a sexualidade. A esse respeito, Foucault (1988) apresenta uma nova leitura da relação entre poder e sexualidade. Embora não negue a existência da repressão em muitos momentos, o autor destaca uma dinâmica mais complexa e mais sutil, posto que concebe que a dominação das pessoas ocorre por meio do controle, de técnicas de sujeição e de métodos de individuação e observação. Nesse contexto, a escola torna-se um espaço onde o poder disciplinar produz saber a fim de dominar com maior eficiência; serve de adestramento para obtenção de corpos vigorosos, obedientes e livres da devassidão. O currículo escolar, por entrecruzar saber e poder, representação e domínio, discurso e regulação, condensa relações de poder interessantes para o processo de formação de determinadas subjetividades sociais.

\section{CONCLUSÕES (IN)CONCLUSAS}

A análise das raízes históricas da sexualidade permite reforçar o argumento de que a sociedade em que vivemos ainda se encontra dividida, hierarquizada e marcada por conceitos e discursos de séculos anteriores que abordam a sexualidade como um objeto a ser escondido e regrado. Apontamos a contribuição de Michel Foucault a respeito da história da sexualidade e da relação saber-poder. Pudemos entender que a repressão não se concentra em um modelo político ou de Estado, mas espalhada em redes de micropoderes que envolvem o ser humano e os seus discursos. Para Foucault (1985), a superação do modelo sexual do capitalismo não passa pela crítica à repressão, mas pelo silenciamento do discurso da sexualidade e do objeto sexo e pela descoberta de uma nova relação com o corpo e com o prazer.

A escolha pela referência foucaultiana justifica-se porque, além de Foucault ser considerado um dos intelectuais de maior influência no pensamento moderno sobre a sexualidade, ele investiga a constituição dessa categoria nos códigos morais ao longo da 
história. Investigar a sexualidade nesse sentido significa buscar compreendê-la a partir das relações de poder que a conformam em cada período da histórico e em cada contexto socioeconômico e cultural que se revela como um negócio de Estado, algo que requer a governamentalização. Isso ocorre porque a conduta sexual da população passa a fazer parte das preocupações da gestão, da economia e da saúde pública, que estão relacionadas à produção de riquezas, à capacidade de trabalho e à força de uma sociedade.

Além do aspecto político-econômico, a Educação Sexual apenas sob uma visão de orientação possibilita vigilância e controle constantes, haja vista que é via de acesso a aspectos da vida, tanto no plano pessoal como no público, e por isso suscita mecanismos de controle que se complementam e instituem o indivíduo e a população como objetos de poder e de saber.

Nesse contexto, a escola é concebida como um espaço de intervenção preventiva de saúde sexual, de cuidados da sexualidade de crianças e jovens, a fim de moldar comportamentos sob leis e diretrizes que regem a "forma correta" de educar. Entendemos que a teoria não pode ser vista como uma receita, um conjunto de regras e conhecimentos aplicáveis a quaisquer contextos, mas, sim elaborada a partir das necessidades concretas da realidade educativa cotidiana. Reafirmamos que a sexualidade é tratada frequentemente como um assunto proibido, constrangedor e vergonhoso. Muitos são os mitos que a envolvem e trazem o sexo como algo feio, sujo, impuro, perigoso e proibido. Sexo e sexualidade não podem ser associados a aspectos negativos e destrutivos. Um enfoque mais assertivo desses aspectos na educação integral da criança poderá evitar desvios e sofrimentos posteriores.

Os primeiros anos de vida são de fundamental importância para o desenvolvimento do sujeito, para a aquisição de valores, atitudes e condutas em relação à vida, ao sexo e à sexualidade. É no início da vida que se encontram as bases da autoestima, da identidade e do desenvolvimento saudável da sexualidade. A Educação Sexual infantil deve considerar as crianças como seres sexuados que manifestam sua sexualidade e criam as próprias teorias sobre sexo.

Devemos também reconhecer que meninos e meninas podem brincar e transitar livremente entre brinquedos e brincadeiras característicos de ambos os sexos, sem o pressuposto de que isso irá definir a identidade sexual. As brincadeiras são caminhos para a descoberta do mundo e do prazer. Uma educação que contribua para o pleno 
desenvolvimento da sexualidade da criança deve centrar-se na formação de valores como amizade, amor, carinho, atenção, companheirismo, lealdade, dignidade e respeito, e não no exercício do poder e do domínio.

As crianças necessitam de pais e educadores conscientes e capacitados para responder às suas questões e curiosidades de forma tranquila e natural, de modo que as ajudem a entender o corpo e suas manifestações e a viver a sexualidade de forma sadia e plena.

A importância de conhecer a respeito da estrutura e da dinâmica do desenvolvimento humano revela a possibilidade de reflexão dos professores a respeito de seu papel de formador. Afinal, juntamente com a família, eles têm por responsabilidade o compromisso de possibilitar à criança condições de se desenvolverem, sempre dentro de um movimento. O processo não é uma linearidade, mas constituído de possibilidades de uma formação crítica a partir da reflexão dos próprios erros e acertos.

Cada sujeito constrói de forma subjetiva seus significados e assim faz suas próprias escolhas. A percepção da realidade e do ambiente que o sujeito ocupa é desenvolvida na medida em que ele faz experiências, enquanto um ser lançado no mundo (HEIDEGGER, 1988) e aberto a possibilidades. Nesse sentido, é necessário que se verta um olhar sobre o homem como um ser de capacidades, de modo que todo aquele que busque ensinar alguém deve prever e garantir sua liberdade criativa de ir à procura do sentido de si. Ora, as referidas capacidades de cada sujeito revelam o seu potencial de autonomia, que, na perspectiva fenomenológico-existencialista, deve ser fomentada e garantida por verdadeiros terapeutas (os "abridores de portas", conforme atesta o termo e sua acepção grega).

Tendo como meta auxiliar a autonomia e autoconscientização crítica do educando/cliente, os educadores/terapeutas devem atuar em seus espaços pedagógicoterapêuticos como facilitadores nesse processo de descoberta do caminho de si mesmo. Este caminho tem de ser criado a partir das concepções existenciais do próprio educando/cliente, numa perspectiva não diretiva, não importando qual seja o caminho e o destino final que esse sujeito-aprendente chegue, desde que o faça de modo autônomo. Em suma, todos os autores que aqui analisamos nos apontam a importância da construção intersubjetiva de interações dialógicas vertidas à promoção emancipatória de 
si e do outro, cenário que, dentre outras coisas, pretere relações de opressão por considerar que todos os envolvidos em settings terapêuticos e em salas de aula têm algo a aprender com o outro.

\section{Notas de rodapé}

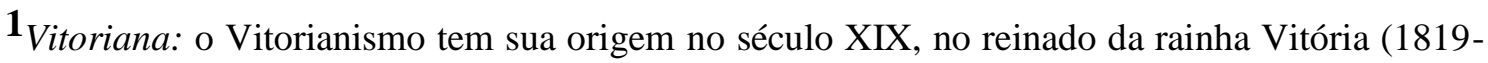
1901), daí seu nome.

$\mathbf{2}$ Libido: energia ou pulsão sexual presente em todas as épocas da vida do indivíduo.

3 "Ars erótica": (arte erótica), que certas civilizações (China, Índia, mundo muçulmano) aplicam à sexualidade, é definida como mistério e assunto passível de um processo de iniciação e aprendizado.

4 Scentia sexualis: opõe-se culturalmente, segundo Foucault (1988) ars erótica, pois procura definir parâmetros nos quais operam a inclusão do que é aceitável no campo da normalidade, e a exclusão do inaceitável. Mas para excluir algo, é preciso estudá-lo conscientemente.

5 Repressão sexual: segundo Chauí (1992), o fato da repressão sexual é antigo, mas o conceito, o estudo de seu sentido, de suas causas e variações no tempo e no espaço é recente.

6 Sodomia: significa coito anal entre indivíduos do sexo masculino ou entre um homem e uma mulher.

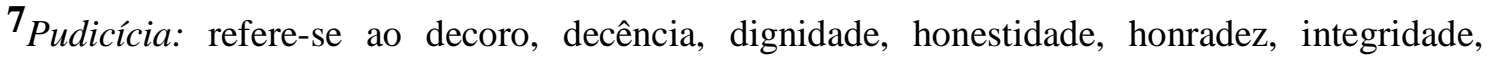
probidade, retidão, respeitabilidade e seriedade.

8 Biopolítica: termo utilizado por Foucault (ano) para designar a forma na qual o poder tende a se modificar no final do século XIX e início do século XX. Anteriormente, as práticas disciplinares visavam governar o indivíduo. A biopolítica é a prática de biopoderes locais e tem como alvo o conjunto dos indivíduos, a população. No biopoder, a população é tanto alvo como instrumento em uma relação de poder.

9 Poder-saber: de acordo com Michel Foucault (1993) existe uma relação íntima entre o conhecimento e o poder dentro da coletividade. Segundo o filósofo, o discurso que ordena a sociedade é sempre o discurso daquele que detém o saber. Esse autor cria uma definição que assevera que o poder do discurso pode funcionar negativamente se distorce a verdade e garante a dominação do opressor. Essa forma de "ameaça" se dá por meio do saber. A "instituição escola" funciona como apoio à vontade de verdade, ao mesmo tempo que distribui, valoriza e reparte o saber. Dessa forma, exerce uma espécie de pressão ou coerção sobre os indivíduos, ao forçá-los sutilmente a se moldar ao que pensa a classe que domina ideologicamente a sociedade.

10 Decurião: entre os romanos, chefe de uma decúria, como instituição administrativa e social; conselheiro que atuava nos senados municipais e coloniais.

\section{REFERÊNCIAS BIBLIOGRÁFICAS}

CHAUÍ, M. Repressão sexual: essa nossa (des)conhecida. Editora Brasiliense, 1992.

COLTRO, A. A fenomenologia: um enfoque metodológico para além da modernidade. Caderno de pesquisa em educação, São Paulo, v.1, n.11, , 2000.

Educação, Psicologia e Interfaces, Volume 2, Número 1, p. 47-70, Janeiro/Abril, 2018 
FOUCAULT, Michel. História da Sexualidade vol. I, A Vontade de Saber. 9. ed., Rio de Janeiro: Graal, 1985.

Microfísica do poder. 11. ed. Rio de Janeiro: Graal, 1993.

Vigiar e punir. Petrópolis, RJ: Vozes, 1998.

FREUD, S. O mal-estar na civilização. Tradução de José Octávio de Aguiar Abreu. Rio de Janeiro: Imago, 1974 (Obras psicológicas completas de Freud, v. 21).

LIMA, T. C. S; MIOTO R. C. T. Procedimentos metodológicos na construção do conhecimento científico: a pesquisa bibliográfica. Rev. Katál., Florianópolis, v. 10 , n. esp., p. 37-45, 2007.

LOURO, Guacira Lopes. Gênero, sexualidade e educação: uma perspectiva pósestruturalista. 3. ed. Petrópolis: Vozes, 1999.

Pensar a sexualidade na contemporaneidade. In: PARANÁ. Sexualidade. Curitiba: SEED - PR., 2009. p. 29 - 35.

Pedagogias da sexualidade. In: da sexualidade. Petropolis: EdAutêntica, 2010. . (Org.). $\mathrm{O}$ corpo educado: pedagogias MARX, Karl. Manuscritos econômico-filosóficos. São Paulo: Bontempo, 2010.

MERLEAU-PONTY, M. Fenomenologia da percepção. São Paulo: Martins Fontes, 1996.

NUNES, César Aparecido. Filosofia, Sexualidade e Educação: as relações entres os pressupostos éticos-sociais e históricos-culturais presentes as abordagens sobre a educação sexual escolar. Tese (Doutorado em Educação) - Faculdade de Educação, Universidade Estadual de Campinas, Campinas, 1996.

Desvendando a sexualidade. Campinas, SP: Papirus, 1987.

\section{Credenciais das autoras}

TRABUCO, Paula Maria. Graduação em Psicologia, Mestre em educação. Pesquisadora Voluntária de Iniciação Científica do Programa de Pós-Graduação em Educação da PUC Goiás Docente do curso de psicologia do Faculdade Morgana Potrich - FAMP e do Centro Universitário de Mineiros - UNIFIMES. E-mail:paulatrabuco@gmail.com .

SIQUEIRA, Teresa Cristina Barbo. Doutora em Educação pela PUC Goiás, Coordenadora da Pesquisa A Corporeidade-Subjetividade do Licenciado de Pedagogia Formado/a pela PUC Goiás Frente às Demandas do Mercado de Trabalho do Programa de Pós-Graduação em Educação da PUC/Goiás. Professora do Departamento de Educação, Psicologia e do Mestrado do PPGE/PUC Goiás. E-mail: teresacbs@terra.com.br.

Endereço para correspondência: Paula Maria Trabuco, Centro Universitário de Mineiros. Rua 22 - Setor Aeroporto, CEP 75.830-000, Mineiros-GO. E-mail: 
paulatrabuco@gmail.com

Como citar este artigo (Formato ABNT): TRABUCO, Paula Maria; SIQUEIRA, Teresa Cristina Barbo. Relações de saber e de poder nos discursos sobre sexualidade. Educação, Psicologia e Interfaces, v. 2, n. 1, 47-70, 2018. DOI: https://doi.org/10.37444/issn-2594-5343.v2i1.117

Recebido: 04/10/2017.

Aceito: 26/03/2018. 